\title{
NEW TIMES, NEW ECONOMICS (WHY IS THE “OLD” ECONOMICS FAILING?)
}

\author{
BALTOWSKI, Maciej
}

The purpose of the paper is to analyse the weaknesses, both epistemological and applicative, of the contemporary orthodox economics and, based thereon, to indicate the necessary changes it needs to undergo. Two groups of weaknesses are distinguished here - the intrinsic ones and the acquired ones. The former ones result from diversity and variability of its object of study and from the teleological nature of the economy. The latter ones, related to the methodological principles of economics stem from errors or omissions committed by the founders of economics in the historical development. The author identifies and analyses three such weaknesses - superficiality of cognition, overformalisation and the delusion of universalisation.

The analysis shows that globalisation processes and other varied civilisational transformations we have been experiencing over the last 15-20 years have brought into light and highlighted the weaknesses of economics. The author comes to the conclusion that consequently the economics for the $21^{\text {st }}$ century, to meet the challenges of the new times, should undergo three basic shifts: $a /$ from positive, descriptive science to including also the evaluative and axiological one; $b$ / from homogeneous, universal science to a considerably contextual one and $\mathrm{c} /$ from pure, formalised science to a deeply interdisciplinary one.

Keywords: economic theory, weaknesses of economics, economics for the future

JEL classification indices: A10, A12, B10, B41, B50

Baltowski, Maciej, Professor of Economics at the Department of Theory and History of Economics, Maria Curie-Sklodowska University (UMCS) in Lublin, Poland. E-mail: maciej.baltowski@umcs. lublin.pl 


\section{INTRODUCTION}

The globalisation processes taking place over the last decade or so had a deeply transformative impact on all areas of life, especially the sphere of economics. The broad homogenisation of the scale of human needs and behaviours, and manufacturing processes, made possible by technological innovation, is integrating national economies into one interdependent global system. Markets researched by the contemporary economics are much unlike those existing a hundred or even fifty years ago. Different characteristics and role than at the time of Adam Smith or Alfred Marshall are attributed to private ownership, another fundamental economic category. Equal footing to that of developed countries is enjoyed in the global economy by countries that used to be, until recently, treated like the Third World, and now pursue their own, effective development paths rather than repeating those followed in the past by the rich Western economies.

In this context, there is a growing realisation that an economics based on the neoclassical, orthodox paradigm, created to study the economic reality which, in fact, is becoming history, has substantially exhausted its descriptive and cognitive capabilities and neither can it offer any reasonable solutions to the mounting economic problems. The conceptual weakness of the mainstream line of thinking can be best illustrated by its ambiguous or even chaotic response to the results of the 2008-2009 financial crisis. In the recent years many renowned economists have been either profoundly critical of the contemporary economics (Kolodko 2011; Rist 2011; McCloskey 2014; Lawson 2015) or have suggested "reconstructing macroeconomic theory" (Stiglitz 2015).

Paul Krugman (2014) does not share this pessimist vision of the contemporary economics. His answer to the question asked in the title of the article ("Why Economics Failed?") is paradoxical. He writes: “...basic textbook macroeconomics has performed very well. But policy makers and politicians have ignored both the textbooks and the lessons of history". And he goes on to ask point blank: "why didn't we use the economic knowledge we had?" Indeed, as observed by Krugman, "policy makers just keep finding reasons not to do the right thing". Still, notwithstanding the above, economics as a science undoubtedly can be charged with a number of serious weaknesses which make it fail nevertheless. Economics fails, meaning, on the one hand - at the epistemological level - that it has an inadequate or even false understanding of the economic reality, including cause and effect relationships and driving forces in the economy. On the other hand - at the applicative level - it has very serious problems formulating the right indications for the economic policy,

The fallibility or imperfection of economics as a science, passing over the fact that politicians do not not always listen to economists, lies in its two kinds 
of weaknesses. Firstly, these are intrinsic, irremovable weaknesses that are part and parcel of the very nature of economics itself, resulting from the specific characteristics of its object of study - diversity and variability - and the teleological nature of the economy. In this respect, economics "must fail", but the goal is to make sure it fails as little and as rarely as possible. Secondly, these are acquired weaknesses inherent in the methodological or metatheoretical principles of economics. These stem from errors or omissions committed by the founders of economics in the historical development. Three of them seem to be of the greatest importance: superficiality of cognition, overformalisation and the delusion of universalisation.

The purpose of this paper is twofold. Firstly, I will attempt to discuss the above-mentioned weaknesses of contemporary economics, both the intrinsic and acquired ones, emphasising their dissimilar sources and nature. Secondly, based thereon I will reflect on the directions economics should take to fail less frequently and to better address the new challenges. I generally conduct my analysis at the macroeconomic level and I consider the relationships between micro- and macroeconomics.

The paper is organised as follows. Section 2 and 3 contain, respectively, a discussion of intrinsic and acquired weaknesses of the economic science. In section 4, I present the impact of recent years' civilisational transformations on the cognitive and applicative capabilities of economics. In section 5, I indicate - in the light of earlier analysis - three directions of change in economics, which are essential, in my opinion, to meet the challenges of modern times.

\section{INTRINSIC WEAKNESSES OF THE ECONOMICS}

Though representatives of various sciences, such as mathematics or philosophy, often emphasise their uniqueness and special nature, for economics such a claim is - in my opinion - fully justified. The specificity of economics stems from two particular features of its object of study, i.e. economy - diversity and variability and from its teleological nature. These features determine the intrinsic, irremovable weaknesses of economics as a science.

\subsection{The issue of diversity and variability of economic systems}

Economics originated and developed in Anglo-Saxon countries as the science of the functioning of a free-market capitalist economy, where the practice of economic freedom and the separation of the economic sphere from the sphere of state 
activity were self-evident. The free-market views of Adam Smith, his glorification of private ownership and entrepreneurship shaped the mindset of the subsequent generations of economists. In mainstream economics, all economy types that are non-free-market and not based on private ownership were and still are treated as non-performing, inefficient "special cases" the true economic science should not be bothered to examine in-depth. As vividly observed by J.E. Stiglitz, economics has moved "from being a scientific discipline into becoming free market capitalism's biggest cheerleader" (2010: 238).

In our time, such an approach derived from the classical and neo-classical tradition seems neither adequate nor methodologically legitimate. In reality, the object of study of the contemporary macroeconomics is not one type of capitalist free-market economy - more or less detached from the ideal model - but rather a number of specific, separate economic systems. These systems, even though their functioning generates comparable outcomes in the form of production of final goods, are very diverse. They have a distinct internal structure, operating principles, regulatory and motivational mechanisms. The form of ownership of their constituent business entities may be different, translating into the way these entities and the economic systems as a whole function. Grzegorz W. Kolodko wrote about it as follows: "As a science, economics must fit reality, and that reality differs over time and space" (Kolodko 2011: 3).

Observations of the economic reality provide convincing examples to support the above statements. Nowadays, there are two giant, significantly diverse economic systems which set the tone for the global economy - the American one and the Chinese one. It would be undoubtedly a methodological fallacy to assume that the competition-based model with the free market mechanism, useful to describe and theoretically understand the US economy and discover its interdependencies can be a good methodological basis for analysing the Chinese economy ${ }^{1}$. However, the Chinese economy is by no means an exception. It is hard to understand the functioning of some of the largest and most powerful economies, namely that of Russia, Brazil or India, if we apply to them the orthodox model of free-market economy with dominant private ownership. It is also the case for many smaller, dynamically growing economies in various parts of the world.

The other specific feature of the object of study of economics, i.e. the variability of economic systems, has quite different nature and consequences. At the time economics emerged and was taking shape, this feature was of relatively little significance. For thousands of years, changes of economic (or socio-economic) systems occured very slowly, at a rate that was imperceptible from a generation's

Terms such as centrally managed capitalism, sino-capitalism, state-led capitalism, or even

"Chinism" (Kolodko 2018) are used with respect to the Chinese economic model. 
perspective. They only picked up the pace from the early $19^{\text {th }}$ century onwards, and in the recent decades we can undoubtedly observe a process of exponential acceleration (McCloskey 2010). There is no doubt that the intensity of those changes has reached such a quantitative and qualitative degree that they cannot be ignored in the cognitive process of the economic science. In economics, as G. W. Kolodko wrote (2011: 286) "the subject under study keeps changing, and this means that the generalizations must change as well".

Variability as a feature of economic systems is unequally distributed. There are economic systems that are stable, and even though they are subject to changes, this happens slowly and, to a great extent, predictably. Those include highly developed economies of Western countries. However, there are also systems that are changing fast and thoroughly, and the directions of those changes are often not easy to decipher. A good example would be post-socialist economies, as well as the so called emerging markets. Observations show that usually they do not replicate the growth paths of countries that were at a similar level of development $30-40$ years ago.

The variability of economic systems is undoubtedly a sign of the times and gives rise to a new, hard-to-solve and - one could say - dramatic problem for economics. It turns out more and more often that the reality as observed by economists is "escaping" them. Upon researching a given fragment of reality, a specific economic system, economics acquires solid scientific knowledge on that subject, except that such knowledge is already historic in nature. It refers to a reality that existed once (this "once" becoming increasingly shorter) but is no longer there today.

It seems that the rich palette of sciences practiced by human beings does not include any other where diversity and variability of its object of study would compare to economics. This creates problems that cannot be entirely solved. An economist can never be sure that their knowledge acquired based on research into economy in place A and time $t$ can be successfully transferred (applied) to an economy in place $\mathrm{B}$ and time $\mathrm{t}+1$.

\subsection{The issue of teleological nature of economy}

Regardless of the deep differences between economic systems studied by economics, they all share one very important characteristic. An economy is always a teleological being, one that exists and functions to serve a specific purpose ${ }^{2}$.

Objects of study of other social sciences, e.g. social systems, can also be attributed teleological characteristics. Still, for the object of study of economics, i.e. economy, this purposefulness is especially significant and clear. 
People create the economy (or - which boils down to the same thing - the economy comes into being as a result of human interactions) to ensure there is production and exchange of goods and services. At the level of metagoals, one can say that the economy exists to ensure a growing prosperity and an ever-improving material dimension of human existence, which is achieved by distributing and consuming products of the economy.

The value of those goods and services in relation to the expenditure necessary to produce them constitutes the key economic characteristic of each economic system. Hence, recognition and understanding of the economy, which is the task of economics as a descriptive science, cannot be only limited to deciphering its constitutive principles, relations between its elements, explaining its "laws of motion", etc. It is also necessary to identify this key characteristic, i.e. the inputto-output ratio, which operationally can take specific forms and measures: performance, productivity, effectiveness or efficiency.

Therefore, the cognitive process of descriptive economics can and should be naturally complemented with a comparison of the input-to-output ratio for different systems studied, which yields a conclusion that is no longer descriptive but rather evaluative - there are economies that are better, more performing, more efficient and more productive (i.e. those producing relatively more of the final product, generating greater prosperity) and those that are lesser (produce relatively less, generate lesser prosperity). Making this kind of comparisons - let me reiterate - as part of the cognitive process of positive (descriptive) economics, directly leads to expressing an opinion (evaluative judgment) in terms of "better-worse" about the economic reality studied, which, traditionally understood, means, in fact, venturing into the realm of normative economics.

In the light of the above exposition of arguments, the classical methodological problem of economics - positive-normative dichotomy (Cassidy 1995; Caplin Schotter 2008) - seems, at least partly, only apparent. If economics can, as part of objective scientific cognition, distinguish between better economies that provide more wealth and worse ones that provide less wealth, that is make an evaluative judgment, the traditional boundary between positive and normative economics becomes blurred to a certain extent. Different operating modes and principles of economic systems lead to different input-to-output ratios. Patterns, laws or principles "discovered" earlier in the course of the analysis of good economies can directly provide a basis for recommendations, guidelines and indications for the economic policy.

However, the matter is not so simple. The above reasoning is correct if: the criteria for what a "good economy" is clear and objective (Sedlacek 2013). That had been the case from the beginnings of the economic science until - more or less the last quarter of the $20^{\text {th }}$ century. Adam Smith gave an unambiguous answer to 
the question about the shape of a good economy. The father of economics had no doubt that - as Mark Blaug writes (1997: 62) - "free-market economy secures the best of all possible worlds". An economic system with a possibly extensive economic freedom and unbridled competition is - according to Smith - more efficient, more productive, more performing, generates more wealth and reduces the extent of poverty faster than any other. Then the criteria for comparing and evaluating economic systems as well as for formulating guidelines for the economic policy based thereon are relatively clear.

However, starting from a certain level of development, when the basic needs of human beings have already been satisfied, when the society as a whole reaches a decent level of consumption and prosperity, the matter gets complicated. Economies still are teleological beings, but the goals furthered by them, and, in consequence, the evaluation criteria and the indications for the economic policy can become significantly diverse. The goals are, to a great extent, linked to the state's activities and are often non-economic in nature, and evaluation criteria cannot be reduced to simple input-to-output ratios, the way it could be done for economies at a low level of development. Hence, the recommendations presented by economics cannot be limited to the economic policy; they must also involve a social policy or geopolitical issues.

Consequently, in all contemporary, diverse economies an objective scientific cognition, irrespective of its quality (which is discussed later, in par. 3.1), cannot provide sufficient groundwork for formulating guidelines for the economic policy as the latter is only a non-autonomous element of the state policy involving a complex of varied issues and goals. The knowledge acquired in the cognitive process of economics must be processed, adjusted to the diverse goals, tasks and evaluation criteria, which are often remote from purely economic issues.

\section{ACQUIRED WEAKNESSES OF ECONOMICS}

\subsection{Superficiality of the cognitive process}

The orthodox economics has never dealt with the cognitive process well enough to ensure that knowledge in that respect provides an adequate theoretical and empirical groundwork for applicative indications. And, in the absence of that, the attempts at making economics an applied science, while being widespread, were doomed to failure, a complete or partial one.

Where does the epistemological weakness of the orthodox economics come from? Why is it that, despite decades of research efforts, despite involving massive funds and the world's best minds in basic research, economics has failed 
to reach satisfactory cognitive results? A good answer to those key questions is provided by the ontological structure of reality, suggested by T. Lawson (1997) as part of his critical realism interpretation. He claims that in the scientific cognitive process in every empirical discipline including economics, a researcher deals with their separate ontological levels: empirical level, actual level and real level.

Using the model created by Lawson, one can say that the full cognitive process in economics involves (or should involve) three subsequent phases:

1. Exploring the empirical reality, which means identifying the existence of and describing economic phenomena and processes.

2. Exploring the actual reality, which means discovering, using a specific theory or research perspective, the dependences/interdependencies and relations/ correlations between empirical data obtained in phase one.

3. Exploring the real reality, which means attempting to understand the reality: revealing the underlying mechanisms, structures and processes that determine both the dependencies formulated in phase two, and their implications, also using a relevant theory or research perspective.

In phase one of the cognitive process, the object of economics is to identify, name and collect data related to economic phenomena and processes. In phase two, it looks for connections and interdependencies between them, which leads to creating a specific economic theory (through induction), or it does so using previously formulated theories (through deduction). In phase three it attempts to explain and understand the causes and determinants of those connections and dependencies, as well as to identify their real consequences, which obviously must also result in creating a "higher order" theory.

It seems that economics as a positive science, as a rule, focuses on phase one and phase two research, rarely moving on to phase three, which is not directly cognitively accessible ${ }^{3}$. This stems from the fact that for economics this third, deepest phase of cognition (or understanding) of reality differs substantially from the two former ones. At the empirical level, as well as, to a great extent, at the actual level, economic phenomena are usually strictly economic in nature. The economic science has developed in this respect relevant formalised methods for data collection, processing and analysis to enable describing and understanding economic phenomena and processes, and it is also capable of developing relevant theories to explain various relations and dependencies between them.

However, this knowledge from phase one and two is not tantamount to an understanding of economic processes, entailing an in-depth cognition of the mechanisms, structures and processes which determine in reality the phenom-

3 What I mean here is orthodox economics. Institutional economics quite often moves to phase three but usually without the adequate "processing" of phase one and two. 
ena observed in previous phases and which are only identifiable in phase three. Meanwhile, this third ontological level of economic reality (and, accordingly, third level of cognition) is largely "non-economic". Those determinant mechanisms, structures and processes often are social, political and cultural rather than economic in nature. To identify, describe and understand them holistic and interdisciplinary perspectives are required which go beyond the traditional cognitive capacities of economics. For this reason, either they are not sufficiently studied and taken into account by orthodox economics, whose representatives lack the appropriate knowledge and skills to do so, or they are simply omitted in research ${ }^{4}$.

A vicious circle of sorts is thus created: economics is unable to go to phase three of scientific cognition as this would require giving up on purely economic perception of reality, adopting a comprehensive and interdisciplinary approach, one looking for a deeper explanation and understanding of economic phenomena outside the sphere of economy, which most economists are neither able nor willing to do. However, failing to achieve phase three of cognition, and stalling instead at phase two, not the final one, economics may not become a mature science, one with well-established knowledge on its object of study; meanwhile, only such a development would create an appropriate basis enabling economics to become an applied (or applicative) science having a reasonable and rational impact on the economic reality.

\subsection{Overformalisation}

Economics as a science came into being in the era of the Cult of Reason and scientific cognition of the world, shaped by the ideas of Descartes and Leibniz. Adam Smith, to a certain extent inspired by the achievements of Newtonian physics (Redman 1993), believed the economic mechanism to be determined by objective laws of economics, and the primary goal of science to discover them. Leading classical and neo-classical economists, from Ricardo until Marshall, focused their efforts mainly on understanding and explaining the operating principles of economy, extending the descriptive method to include elements of deduction. It was this very initial stage of development of economics, mainly thanks to $\mathrm{N}$. Senior and J. S. Mill, and then L. Walras and others, that saw a widespread ten-

4 Of course many economists, especially those representing the institutional school, are fully aware of that. G. Myrdal wrote already many years ago: "In regard to practically every economic problem, scientific study must concern the entire social system, including, besides the so-called economic factors, everything else of importance for what comes to happen in the economic field" (Myrdal 1976: 82). 
dency to view economics as a pure science whose goal is to discover, formulate and justify universal theorems and laws rather than seeking and recommending applicative (practical) solutions.

Neoclassical economists believed that economics should be a formal and axiomatic science that derives its theorems from premises relating to human beings' elementary economic behaviours. To them, any evaluative or prescriptive considerations would fall under normative economics, treated ever since the times of N. Senior as the art of economics, separate from the sphere of science of economics. Such an approach transformed over time into the "mainstream economics", a highly mathematised, pure and deductive science, which is, by definition, far from any attempts at judging the economic reality.

Further major changes in the development of economics as a pure science took place in the form of the so called formalist revolution (Blaug 2003; Landreth Collander 2002: ch. 14), involving Samuelson, Arrow and Debreu. Since then, the rigour of deductive reasoning and the triumph of mathematised form over economic substance became the attributes of scientific thinking in economics. All the potential of economics and economists, and the bulk of research efforts were directed towards deep formalism. Persistent attempts to make economics a science where, after the fashion of natural sciences, immutable, universal and ahistorical laws and principles reign supreme to be discovered by researchers yielded a lot of studies using sophisticated mathematical and statistical methods, which, however, did not bring the expected applicative results. An economics that focuses on quantitative relations is excellent at analysing and comparing partial empirical data, while doing relatively poorly at explaining underlying causes and real sources of the phenomena under examination.

Of course formalisation has its undeniable advantages when it comes to analysing statistical data and the reliability of the conclusions drawn therefrom. However, the problem is that formalisation mostly involves strictly economic data and relations, so it refers to phase one and two of cognition in the framework of the above presented model. Meanwhile, a deeper cognition, that of phase three, is very hard to formalise as political, cultural or social characteristics and interdependencies are inherently qualitative in nature, as opposed to economic data, which are quantitative as a rule. It can be said, therefore, that formalisation is, to a certain extent, a way for economists to run away from major issues that hardly lend themselves to a strict mathematised analysis.

It must be added that, regardless of the dominant position of formalised and econometric papers (Espinosa et al. 2012), recent years have seen a comeback of the grand historical narrative in economics. One can mention here, for example, the widely commented books by McCloskey (2010) or Acemoglu - Robinson (2012). Irrespective of all the substantial differences between them in terms of 
how they explain the causes of growth in the long run (or, in fact, the basic Smithian problem of the sources of the wealth of nations), what they have in common is the realisation of paramount importance for these deliberations - that, at a deep level, economic phenomena and processes depend on considerably non-economic factors. Similar views are also expressed by Kolodko, who writes about it directly: "If we survey the history of development and stagnation, we see that history has one clear lesson to teach us: Culture is decisive. [...] Economists don't like to hear such declarations" (2011: 310).

\subsection{Delusion of universalisation}

Treating economics as a theoretical science akin to natural sciences means that its goal is to discover and explain objectively existing and generally applicable laws and principles of economic processes. Landreth and Collander note that, notwithstanding all the differences between Smith, Ricardo and Mill, they were unanimous on this fundamental point: "They presumed that economic theory was universally true, equally applicable to different periods in history and to societies with markedly different structures" (2002: 312).

It seems that searching for universal laws of macroeconomic management, the founding axiom of this science since the inception of economics, was for decades one of the major reasons for its weakness. Economic systems are diverse and variable entities, whose regulatory mechanisms are non-economic in nature at the deepest underlying level. Hence any attempts to find universal laws and regularities relating to all of them and each one individually are doomed to fail. They only lead to formulating highly generalised statements which are praxeological rather than economic in nature, and contribute little to the understanding of the diverse economic processes and phenomena occurring in reality.

When writing about International Monetary Fund's economic recovery programmes, Kolodko notes an interesting aspect of the needless universalisation with respect to applicative issues: "More than one country has paid a high price for disdaining regional and national differences under the widely proclaimed but naive neoliberal slogan 'one size fits all', which is a call for ignoring local differences in the application of economic policy" (2011: 7).

In the recent years, amid a clear diversity and variability of economic systems, which I discussed before, there is a growing shift towards the view I fully subscribe to that assuming the existence or even just looking for universal laws leads economists into a cognitive cul-de-sac. This point of view is well illustrated by the quote from a paper by eminent American economists Acemoglu and Robinson (2015:3): "[...] the quest for general laws of capitalism is misguided because 
it ignores the key forces shaping how an economy functions: the endogenous evolution of technology and of the institutions and the political equilibrium that influence not only technology but also how markets function and how the gains from various different economic arrangements are distributed".

There is one more important dimension to needless universalisation in economics, which involves the relationship between micro- and macroeconomics. For the classicists - Smith, Ricardo or Mill - it was obvious that "an understanding of the entire economy was best achieved by starting at the level of the household and the firm" (Landreth - Colander 2002: 313). Subsequent generations of economist followed a similar mindset until Keynes, who broke this traditional way to analyse economy - his macroeconomic theory was essentially devoid of microeconomic foundations. Nevertheless, after World War II, leading economists, including Nobel Prize winners, made considerable efforts to create a "universal theory" combining the neoclassical microeconomics with Keynesian macroeconomics. Those efforts - clearly reminiscent of the attempts of theoretical physics to create a "theory of everything" combining quantum mechanics with the general theory of relativity - yielded some model solutions at a high level of abstraction and generality ${ }^{5}$ but failed to bring fully satisfactory results.

A careful look at the contemporary economy calls into question the possibility of developing a highly "failsafe" economic theory consolidating microeconomics and macroeconomics into one. Already within microeconomics, the underlying human economic behaviours are so culturally and environmentally diverse - as demonstrated by behavioural economics - that the traditional idealisations (generalisations) regarding business entities' utility maximisation or rationality seem hard to accept. And notwithstanding the above, considering the diversity of economic systems and the diversity of objectives to be met by economies, the operating principles of enterprises, households and markets quite poorly translate into final outcomes of the economic activity. They translated visibly well in the $19^{\text {th }}$ century, in the economies of the then well-developed West, when the role of government in the economy was relatively minor. Meanwhile, the current active role of government and economic policy, determining the economy's ability to generate and distribute wealth, is clearly loosening the relations between microeconomics and macroeconomics. Indeed, governments very often take decisions that are irrational in the sense of orthodox economics, meaning the political or social logic, which prevails at the macroeconomic level, takes precedence over the economic logic, which still prevails at the microeconomic level.

5 Its peak achievement was the so called neoclassical synthesis of Samuelson and Hicks. 


\section{THE IMPACT OF RECENT YEARS' CIVILISATIONAL TRANSFORMATIONS ON THE CONDITION OF THE ECONOMICS}

The radical, deep and diverse civilisational transformations we have been experiencing over the last 15-20 years have brought into light and highlighted the weaknesses of economics, both the intrinsic and the acquired ones. At the same time, they have broadened - in quite an unexpected direction - its research area and research problems.

The "end of history", the victory of free-market capitalist system in its rivalry against the socialist system, by no means - as it quickly turned out - led to an absolute and permanent hegemony of the former one. Globalisation, which started in earnest soon after the collapse of socialism, made the world realise how different and dissimilar to the classical Western model contemporary economic systems as well as their objectives and operating modes can be. Globalisation has included in the mainstream global politics and economy some large and important countries that, for decades, from the perspective of the West, were treated as peripheries, as the "Third World", such as China, India, Brazil, Indonesia or "second world", the socialist one, such as Russia or Poland.

A dozen or so years ago it was vividly revealed that the civilisation of the West is ceasing to be the only one to generate progress and prosperity, the way it used to be for 200 years, when production (measured with the size of GDP) within a small territory referred to as the "rich West" would rise twice as fast as elsewhere. In this sense, globalisation brought out the importance of the cultural context of economic activity, and, consequently, the epistemological weakness of economics as a science oriented to studying the free-market capitalist system in its Western variety. At the same time, globalisation challenged the very existence of (and the point of looking for) one economics relying on generally applicable universal laws.

Another implication of globalisation, which partly stems from the above, was to bring out and bare the considerable civilisational stratification on the one hand, including the material one, and the equally huge environmental threats, on the other. The side-by-side existence of rich countries with a per capita GDP of up to 45,000 USD and countries that are 50 times poorer, with a per capita GDP of 900 USD, or the climate change caused by human actions, are the symptoms of the lack of elementary worldwide economic order in axiological respect. In the long run, in the context of globalised reality, this can lead to the worst possible consequences for the planet as a whole, for the human existence.

In this sense, the changes taking place over recent years clearly demonstrate the need for economics that is more than a descriptive science aimed to under- 
stand and explain the reality. Of equal importance is for economics to be a rightful evaluative science able to compare and evaluate economic phenomena and processes and based thereon suggest the best solutions to politicians both at the level of diverse economic systems and at the global level.

The third important implication of globalisation does not directly involve the above mentioned weaknesses of the traditional economics, but it shows very clearly the incompatibility or inadequacy of the "old economics" with regard to the "new times". Globalisation has created new, previously non-existent research areas that the traditional economics ill-positioned enough or insufficient to explore. Firstly, globalisation has revealed the fundamental conflict between economies at the national level and the global economy as a whole. The major signs of that conflict include such threats to the world's economic stability as the fallibility of global markets, and global externalities whose effects cannot be corrected by the economic policy at the level of nation-states or even regional integration groups. The fundamental problem of the "old economics" of the last 80 years, i.e. the government - market relations, is transforming itself, before our eyes, into a wider and more difficult problem of coordinating and regulating global markets. Kolodko wrote about this as follows: "The world is facing new challenges as globalization has entered a new stage. What should we expect in terms of interrelations between not only market and government but also [...] market, government and the world?" (2014: 135).

Secondly, over the last decade, after the 2008-2009 financial crisis, a generally stronger and extended role of the government in economy as well as a surge of protectionism have been noticeable. Hybrid economic systems, referred to as state capitalism (Mussachio - Lazzarini 2012) are surfacing, where, with the core institutional and functional tissue of free-market capitalism intact, the role of government is not only way more significant but also different than in the old times. In those systems "governments manipulate market outcomes for political purposes" (Bremmer 2010: 5) as well as usurp (and exercise) the right to discretionally shape the directions of economic development, and long-term macroeconomic goals, as well as to define the groups of beneficiaries to be provided with actual access to the economic surplus generated.

In both of those areas, the traditional macroeconomics does not have either the right language or the right tools to describe and understand the new phenomena and processes, which are not so much strictly economic as political and economic or economic and cultural in nature, even though they determine very strongly the economic behaviours. 


\section{WHAT SHOULD ECONOMICS FOR THE $21^{\text {ST }}$ CENTURY BE LIKE?}

In the light of the above presented analysis indicating the weaknesses of the traditional orthodox economics, to meet the challenges of the new times, economics should, in the methodological sense, undergo three basic shifts:

a) from positive, descriptive science to including also the evaluative and axiological one,

b) from homogeneous, universal science to a considerably contextual one,

c) from pure, formalised science to a deeply interdisciplinary one.

\section{Re: a)}

It is obvious that the principal task of each science is to explain and account for the reality examined. Yet, in the case of contemporary economics, this is not a sufficient task. Two new important areas can be observed where economics for the future may not be indifferent to axiological issues so it must be both a positive and normative science. The first area involves a global level: economics should make attempts to give the concept of economic rationality a new, broader and global meaning. Economics must give up on its classical assumption, formulated in pre-globalisation times, that the maximalisation of wealth paradigm drives the economy. It must shift towards economics of moderation, economics of enough (Coyle 2011), one capable of developing - at least in conceptual terms - the tools to ensure a long-term world balance not only in economy but also in areas directly linked to economy by mutual feedbacks - social and environmental ones. Economics of moderation - as Kolodko wrote (2014a: 415) - "means adapting the volume of human, natural, financial and material flows to the requirement to keep a dynamic balance".

Another area involves the macroeconomic level and stems from the fact that these days, in the context of diversity of economic systems, their goals are not determined objectively by markets, as assumed by traditional model-based perspectives, but subjectively by states and governments. In this sense, economics must be able to formulate active development programmes, which are adapted to specific time and place, oriented to achieve diverse goals, and, therefore, based on different axiological premises.

\section{Re: b)}

Economy as a manifestation of human activities becomes diverse mostly by being strongly embedded in culture. Culture and the attendant axiological system define the attitude of human beings to the environment in which they live, and shape the behavioural patterns in all spheres of human activity, hence also in the economy. Therefore, it is obvious that an in-depth understanding of broadly de- 
fined operating principles of an economic system is only possible from the level of "culture", which is contextual in nature.

Economics for the future must approach, on an equal footing, with equal intellectual humility and curiosity, all the diverse and variable economic systems forming a global whole, regardless of their respective levels of development, structure and the driving forces that organise them. This means moving from universal research methods and applicative indications to tailor-made solutions.

\section{Re: c)}

Economics should take account of the fact that the determinants of economic behaviours, especially at the macroeconomic level, are essentially non-economic; that the principles and outcomes of the functioning of economic systems are, as a matter of fact, determined by an often random nexus of varied factors - predominantly political ones but also cultural, social or even psychological in nature. This interdisciplinary dimension of economics, of crucial importance to the sphere of cognising and explaining economic phenomena, as discussed by me above, is important also in the economic policy, hence in the applicative part of economics.

For example, nowadays in many countries such as China, India or Russia, and even France, the government's impact on the economy through large and significant state-controlled enterprises cannot be overlooked. Especially that these entities indeed pursue non-economical goals such as the state's foreign expansion, protecting domestic economy against the influence of global corporations or even ensuring various sorts of rents to the state apparatus - or goals that are quite remote from the classical maximisation of profit or value growth.

Last but not least, as I have already mentioned, irrespective of the three above listed directions of changes, economics for the future must, in all fields of its activity, take account of the depth and irreversibility of globalisation processes, thoroughly examine the relations between economic systems (at nation-state level) and the global economy (at the transnational level). Economics should create and provide politicians with the tools to coordinate the economic policy at the global level, which is a prerequisite for avoiding cataclysms on a civilisational scale in this area (Tirole 2017).

\section{FINAL COMMENTS AND CONCLUSIONS}

When Adam Smith was laying the foundations for economic science nearly 250 years ago, and when, slightly later, David Ricardo was laying foundations for the contemporary economic analysis, their view and understanding of the world, like that of a great majority of the then thinkers, were far from today's percep- 
tion of reality. There was a universal acceptance of the Leibnizian concept of the "best possible world" - a world as a harmonious or even, to a certain extent, programmed mechanism created by God. This naturally made economists inclined to look for universal laws that describe and explain the functioning of that mechanism. It seemed that to discover those laws, to cognise and understand economy - after the fashion of natural sciences - is the main goal of economics.

However, this cognitive optimism, so characteristic of the rationalism and empiricism era, today belongs with the history of ideas. The world, social life and the economy have proved much more complex, variable and diverse than believed in early $19^{\text {th }}$ century. On the one hand, global interdependencies (as well as global corporations) have a major impact on respective national economies. On the other hand, democratically elected leaders and governments set long-term goals of the economic development, determining themselves, at the level of nation-states, their own "best possible worlds" which are then pursued - at least to a certain degree - in a constructivist manner.

Due to the unique characteristics of its object of study, i.e. economy, economics is a very particular social science, which will never achieve the status of an exact science. A greater part of the observed weaknesses of economics, both the cognitive and applicative ones, referred to hereinabove as intrinsic, are unavoidable, as they are part and parcel of this science. However, another group of weaknesses of economics, the one greatly exposed by civilisational transformations of the last 10-15 years, seems possible to overcome - economics must change. Economics must transform into an applicative science that indicates rational programmes and development goals as well as methods to achieve them, into a contextualised science that shows solutions adapted to the needs of a specific time and place and into an interdisciplinary science that leverages knowledge and research methods from various disciplines.

Of course economists are not blind to the changes taking place in the economy. For several decades now, major schools of heterodox thinking have been present in economics, which rely on different methodological assumptions and have a different perception of economic phenomena and processes than those adopted by orthodox economics. This is true, first and foremost, of different varieties of institutional economics, especially of new institutional economics, but also of physical economics, radical economics, complexity economics or law and economics. In the last 10-15 years, this new economic mindset has been gaining ground. Research centres devoted to "new economics" have been cropping up, such as the Institute for New Economic Thinking at the Oxford Martin School. Also associations of "differently minded" economists such as, for example, "Evonomics" (www.evonomics.com), whose motto is close to the views presented above: 
"Changes in economic thinking can change the world, for the better. That's the core belief that inspires Evonomics".

Kolodko has been, for many years now, one of those - still not numerous economists who do not limit themselves to criticising economics, but also put forward proposals for its far-reaching transformations. His concept called New Pragmatism, presented in his subsequent publications (Kolodko 2011, 2014a, $2014 \mathrm{~b}$ ) in the form of a relatively comprehensive though not fully formalised theory, was also a major inspiration for this paper. Kolodko sees New Pragmatism as a non-orthodox economic theory, and even more broadly, as a theory of social sciences oriented to applicative uses of scientific knowledge, not only on the macroeconomic scale but also on the global one.

Kolodko, as the $19^{\text {th }}$ century fathers of economics did, believes in the power of reason and science as a tool for a rational analysis of reality. However, he is convinced that nowadays the fundamental issues of creating a better economy and a better world depend mainly on state-level decisions and on states' coordinated cooperation on the global level. In this sense he transposes the assumption of rational behaviours of consumers and producers, on which neoclassical economics is founded, to a higher level - that of a rational behaviour of governments, rational economic policy. He writes: "The institution of enlightened interventionism will pass the test if it is used pragmatically rather than ideologically, for economic rather than political reasons" (Kolodko 2011: 333).

The fundamental message of New Pragmatism at a metaeconomic or even philosophical level rather than just the economic one, seems deeply humanist and rationalist, though Kolodko's rationalism goes well beyond the traditional homo oeconomicus model or the more contemporary perspective of G. Becker. Kolodko writes (2010: 10): "The world [...] can be grasped intellectually. Never in all respects and never fully, but to a great extent. The greater one the broader and the deeper our perspective on this reality is. Broader and deeper must mean interdisciplinary and non-orthodox, critical and progressive, bold and unconventional. When such a rational grasp of the surrounding reality is successfully achieved, one can try and change it for the better, following the perennial human desire, which is the source of all progress".

\section{REFERENCES}

Acemoglu, D. - Robinson, J. A. (2012): Why Nations Fail: The Origins of Power, Prosperity, and Poverty. New York: Random House.

Acemoglu, D. - Robinson, J. A. (2015): The Rise and Decline of General Laws of Capitalism. Journal of Economic Perspectives, 29(1): 3-28. 
Blaug, M. (1997): Economic Theory in Retrospect. $5^{\text {th }}$ ed., Cambridge: Cambridge University Press.

Blaug, M. (2003): The Formalist Revolution of the 1950s. Journal of the History of Economic Thought, 25(2): 145-156.

Bremmer, I. (2010): The End of the Free Market: Who Wins the War Between States and Corporations? New York: Portfolio.

Caplin, A. - Schotter, A. (eds): (2008): The Foundations of Positive and Normative Economics: $A$ Handbook. Oxford, New York: Oxford University Press.

Cassidy, J. (1995): The Is-Ought Problem and the Ground of Economic Ethics. Humanomics, 11(1): 92-149.

Coyle, D. (2011): The Economics of Enough: How to Run the Economy as if the Future Matters. Princeton: Princeton University Press.

Espinosa, M. - Rondon, C. - Romero, M. (2012): The Use of Mathematics in Economics and its Effect on a Scholar's Academic Career. MPRA Paper, No. 41363.

Kołodko, G. W. (2010): Świat na wyciagnięcie myśli (The World at the Extent of Thought). Warszawa: Prószyński i S-ka.

Kolodko, G. W. (2011): Truth, Errors and Lies. Politics and Economics in a Volatile World. New York: Columbia University Press.

Kolodko, G. W. (2014a): Whither the World: The Political Economy of the Future. New York: Palgrave Macmillan.

Kolodko, G. W. (2014b): The New Pragmatism, or Economics and Policy for the Future. Acta Oeconomica, 64(2):139-160.

Kolodko, G. W. (2018): Capitalism, Socialism or Chinism? Communist and Post-Communist Studies, 51(4): 285-298.

Kolodko, G. W. - Postula, M. (2018): Determinants and implications of the Eurozone Enlargement. Acta Oeconomica, 68(4): 477-498.

Krugman, P. (2014): Why Economics Failed? The New York Times, May 1.

Landreth, H. - Colander, D. D. (2002): History of Economic Thought. $4^{\text {th }}$ ed., Boston MA: Houghton Mifflin.

Lawson, T. (1997): Economics and Reality. London and New York: Routledge.

Lawson, T. (2015): Essays on: The Nature and State of Modern Economics. London and New York: Routledge.

McCloskey, D. (2010): Bourgeois Dignity: Why Economics Can't Explain the Modern World. Chicago: The University of Chicago Press.

Mussachio, A. - Lazzarini, S. G. (2012): Reinventing State Capitalism: Leviathan in Business, Brazil and Beyond. Cambridge, Mass: Harvard University Press.

Myrdal, G. (1976): The Meaning and Validity of Institutional Economics. In: Dopfer, K. (ed.): Economics in the Future. London: Palgrave Macmillan, pp. 82-89.

Redman, D. A. (1993): Adam Smith and Isaac Newton. Scottish Journal of Political Economy, 40(2): 210-230.

Rist, G. (2011): The Delusions of Economics: the Misguided Certainties of a Hazardous Science. London: Zed Books Ltd.

Sedlacek, T. (2013): Economics of Good and Evil: The Quest for Economic Meaning from Gilgamesh to Wall Street. New York: Oxford University Press.

Stiglitz, J. E. (2010): Freefall: America, Free Markets, and the Sinking of the World Economy. New York, London: W. W. Norton \& Company.

Stiglitz, J. E. (2015): Reconstructing Macroeconomic Theory to Manage Economic Policy. In: Fruitful Economics. London: Palgrave Macmillan, pp. 20-56.

Tirole, J. (2017): Economics of the Common Good. Princeton: Princeton University Press. 